\title{
Role of plasminogen activator inhibitor type 1 (PAI-1) in PCOS patient
}

\author{
Shikha Sahay ${ }^{1}$, Madhu Jain ${ }^{1 *}$, D. Dash², Lavina Choubey ${ }^{1}$, Shuchi Jain ${ }^{1}$, T. B. Singh ${ }^{3}$
}

${ }^{1}$ Department of Obstetrics and Gynecology, ${ }^{2}$ Department of Biochemistry, ${ }^{3}$ Department of Community Medicine, Institute of Medical Sciences, Banaras Hindu University, Varanasi, Uttar Pradesh, India

Received: 08 July 2017

Revised: 08 August 2017

Accepted: 11 August 2017

\section{*Correspondence:}

Dr. Madhu Jain,

E-mail: drmadhujainbhu@gmail.com

Copyright: (C) the author(s), publisher and licensee Medip Academy. This is an open-access article distributed under the terms of the Creative Commons Attribution Non-Commercial License, which permits unrestricted non-commercial use, distribution, and reproduction in any medium, provided the original work is properly cited.

\section{ABSTRACT}

Background: There has been few studies done demonstrating elevated level of PAI-1 in women with Polycystic Ovarian Syndrome (PCOS). PAI-1 has been associated with insulin resistance, obesity, anovulatory infertility, increased risk of cardiovascular disease in PCOS patient. The objective of the study was to find out the plasma level of PAI-1 in PCOS and compare with healthy age matched control. To correlate PAI-1 with various demographic, anthropometric, biochemical and hormonal parameters in PCOS patient and specific relation of PAI- 1 with the insulin resistance, obesity, hyperandrogenemia.

Methods: A prospective case control study was carried out in 50 patients having PCOS (fulfilling Rotterdam Criteria, 2003). 25 healthy age matched control were taken. Blood samples were taken for estimation of fasting glucose, fasting insulin, lipid profile, LH, FSH, Prolactin, Testosterone, insulin sensitive indices (HOMA-IR, glucose: insulin ratio). Plasma level of PAI-1 was estimated with Human ELISA invitorgen kit. The data were statistically analysed with SPSS 16.0 version (student T test, Pearson ranked correlation coefficient, linear regression analysis was applied) and PAI-1 was correlated with various parameters.

Results: Mean level of PAI-1 was significantly raised in PCOS patient $(893.36 \pm 234.97) \mathrm{pg} / \mathrm{mL}$ than in control (259.68 \pm 97.75$) \mathrm{pg} / \mathrm{mL}(\mathrm{p}<0.001)$. PAI-1 significantly correlated with insulin resistance, obesity; that is; PAI-1 significantly correlated with BMI $(r=0.557 ; p<0.001)$, waist: hip ratio $(r=0.550 ; p<0.001)$, fasting glucose $(r=0.429$; $\mathrm{p}=0.002)$, fasting insulin $(\mathrm{r}=0.357 ; \mathrm{p}=0.001)$, triglyceride $(\mathrm{r}=0.492 ; \mathrm{p}=0.000)$, LDL $(\mathrm{r}=0.604 ; \mathrm{p}=0.001)$, HOMA-IR $(\mathrm{r}=0.467 ; \mathrm{p}=0.001)$. On regression analysis LDL, fasting insulin, HOMA-IR altogether explained $54.9 \%$ of total variability of PAI-1.

Conclusions: Plasma level of PAI-1 is elevated in PCOS patient and it is significantly correlated with insulin resistance and obesity.

Keywords: Insulin resistance, Obesity, PAI-1, PCOS

\section{INTRODUCTION}

Till now, only few studies have been carried out to show association between PAI-1 and PCOS, so we picked PAI1 in our study to establish its definite role in PCOS. PCOS is a complex metabolic, endocrine and reproductive disorder affecting around $5-10 \%$ of the female population in developed countries. Now a day the prevalence of PCOS is rising in developing countries like India, where there is now rapid nutritional transitions due to westernized diets and lifestyle.

Plasminogen activator inhibitor-1(PAI-1), is inhibitor of tissue-type and urokinase -type plasminogen activators (tPA and uPA), which convert plasminogen to plasmin. PAI-1 is a member of serine protease inhibitor 
superfamily, also known as Serpin E-1. PAI-1 is synthesized by many tissue and cell types, free PAI-1 is relatively inactive in its free form and readily converts into it latent form.

The plasminogen activator system through degrading fibrinolytic activities can be explained in the pathogenesis of polycystic ovary syndrome (PCOS). Increased plasminogen activator inhibitor-1 (PAI-1) or tissue plasminogen activator (tPA) activity promote thrombosis by inhibiting the production of fibrinolytic enzyme plasmin, which is significant risk factor for cardiovascular disease.

\section{METHODS}

This study was prospective case control study, carried out in which 50 patients having polycystic ovarian syndrome (fulfilling Rotterdam Criteria, 2003) from outpatient Department of Obstetrics and Gynecology, Sir Sunderlal Hospital between 20013 and 2015 in collaboration with the Department of Biochemistry were included in the study and 25 healthy age matched volunteers were taken as controls. The study was approved by the Institute Ethical Committee and informed consent was taken by the study subjects having following inclusion and exclusion criteria:

\section{Inclusion criteria}

Rotterdam Criteria (2003) was used to diagnose PCOS.

\section{Exclusion criteria}

- Patient with symptoms of Cushing's syndrome, nonclassical congenital adrenal hyperplasia, Hyperprolactinemia, primary hypothyroidism, acromegaly, premature ovarian failure, virilising adrenal or ovarian tumour, primary hypothalamic amenorrhea

- OCPs use within last 4 months and

- Adolescent patient not attended menarche yet or who had attained within 6 months.

For control group, regular menstrual cycle, absence of hirsutism, alopecia and acne, absence of polycystic ovary on sonography and normal hormonal parameters including TSH, testosterone, prolactin, LH, FSH, LH: FSH ratio were included in the study.

A detailed history of patients was taken. Examination was done to look for any features suggestive of acne, hirsutism, acanthosis nigerians, androgenic alopecia, thyroid swelling, galactorrhea with other gynaecological examination. BMI, Waist hip ratio was calculated.

Blood investigations were taken for both cases and controls: serum LH, FSH, Prolactin, TSH, Testosterone, fasting glucose, fasting insulin, cholesterol, triglyceride, HDL, LDL. ultrasound pelvis.
Quantitative determination of serum PAI-1 concentration was measured using HUMAN PAI-1 ELISA (Enzyme Linked Immunosorbent Assay) kit manufactured by Invitrogen.

\section{Statistical analysis}

The analysis was done with the help of SPSS 16.0 version for windows. Numerical data were presented in the form of mean + standard deviation and quantitative data were shown in the form of number and percentage. Student-t-test was used to compare the significant difference in mean values between cases and control groups. Parametric One-way analysis of variance test was applied to find out the significant difference in mean values if groups were more than two. If this test showed the significant difference then posthoc test (Student newmanKuel test) was applied to find pairwise difference. Chi square test was used to test the significant association between the qualitative variables. Correlation were determined by Pearson ranked correlation coefficient. Linear correlation coefficient was calculated to see the amount and direction of relationship between quantitative variables. To estimate the value of dependent variable on the basis of known values of independent variable, if correlation was significant, linear regression analysis was used. P-value $<0.05$ considered as statistically significant.

\section{RESULTS}

The demographic characteristics of each group are compared in Table 1. The mean PAI-1 level in PCOS was $893.36 \pm 234.97 \mathrm{pg} / \mathrm{mL}$ and in control group the means level was $259.68 \pm 97.75 \mathrm{pg} / \mathrm{mL}(\mathrm{p}<0.001)$. The difference was significantly increased in PCOS group as compared to control.

Serum PAI-1 level at $370.1 \mathrm{pg} / \mathrm{mL}$ has $100 \%$ sensitivity and $92 \%$ specificity with confidence interval 0.9921 to 1.003 , area under curve $=0.9976$ (likelihood ratio $=12.5)$. To correlate demographic parameters like age, parity, marital status, socioeconomic status, menstrual pattern, acne and hirsutism with PAI-1 there was significant positive correlation was found with age $(r=0.003$, $\mathrm{p}=0.003)$ and parity $(\mathrm{r}=0.046, \mathrm{p}=0.046)$ in PCOS cases. The correlation of biochemical and hormonal parameters with PAI-1 in PCOS cases was depicted in Table 2 and Figure 1. Among cases, PAI-1 had significant positive correlation with BMI $(\mathrm{p}<0.001)$; Waist: Hip ratio ( $p$ $<0.001)$; Fating glucose $(\mathrm{p}=0.002)$; Fasting insulin $(\mathrm{p}=0.011)$; Triglyceride ( $\mathrm{p}=0.000) ;$ HDL $(\mathrm{p}=0.005) ; \mathrm{LDL}$ $(\mathrm{p}=0.001)$; HOMA -IR ( $\mathrm{p}=0.001)$. Among cases, PAI-1 had significant negative correlation with glucose: insulin ratio $(\mathrm{p}=.003)$; HDL $(\mathrm{p}=0.005)$ that is PAI-1 level decreases with increase in these values. A regression analysis was applied keeping PAI-1 as dependent variable and all those positive predictive parameters (BMI; waist: hip ratio; fasting glucose; fasting insulin; HOMA IR; triglyceride; LDL) (Table 3). 
Table 1: Demographic, biochemical, hormonal parameters in study population (mean+SD).

\begin{tabular}{|llll|}
\hline Parameters & $\begin{array}{l}\text { Study Population } \\
\text { PCOS }(\mathbf{n}=50)\end{array}$ & Control $(\mathbf{n = 2 5})$ & p-value \\
\hline Age $(\mathrm{yrs})$ & $22.26 \pm 3.927$ & $23.80 \pm 3.122$ & 0.092 \\
\hline BMI $(\mathrm{kg} / \mathrm{m} 2)$ & $23.74 \pm 3.91$ & $20.01 \pm 2.32$ & $<0.001$ \\
\hline Waist: hip ratio & $0.74 \pm 0.13$ & $0.50 \pm 0.06$ & 0.424 \\
\hline Fasting glucose (mg/dL) & $95.87 \pm 9.09$ & $93.04 \pm 21.49$ & $<0.001$ \\
\hline LDL $(\mathrm{mg} / \mathrm{dL})$ & $87.06 \pm 14.182$ & $60.96 \pm 14.117$ & $<0.001$ \\
\hline HDL $(\mathrm{mg} / \mathrm{dL})$ & $42.92 \pm 8.538$ & $52.60 \pm 5.074$ & $<0.001$ \\
\hline TRG $(\mathrm{mg} / \mathrm{dL})$ & $181.48 \pm 31.701$ & $152.96 \pm 18.288$ & 0.426 \\
\hline Chol $(\mathrm{mg} / \mathrm{dL})$ & $153.94 \pm 19.81$ & $150.28 \pm 16.05$ & $<0.001$ \\
\hline LH $(\mathrm{mIU} / \mathrm{mL})$ & $17.80 \pm 9.25$ & $4.05 \pm 2.66$ & 0.663 \\
\hline FSH $(\mathrm{mIU} / \mathrm{mL})$ & $5.48 \pm 2.25$ & $5.74 \pm 2.90$ & $<0.001$ \\
\hline LH: FSH ratio & $3.27 \pm 1.06$ & $0.73 \pm 0.34$ & 0.727 \\
\hline TSH $(\mathrm{IU} / \mathrm{mL})$ & $2.94 \pm 1.88$ & $2.80 \pm 1.02$ & 0.050 \\
\hline PRL $(\mathrm{ng} / \mathrm{mL})$ & $20.4088 \pm 24.71135$ & $10.2879 \pm 7.43867$ & 0.024 \\
\hline Testosterone $(\mathrm{ng} / \mathrm{dL})$ & $28.99 \pm 30.93$ & $14.19 \pm 12.05$ & $<0.001$ \\
\hline Fasting insulin & $7.9422 \pm 5.72596$ & $1.7880 \pm .65149$ & $<0.001$ \\
\hline HOMA IR & $1.8831 \pm 1.29402$ & $.4237 \pm .24914$ & $<0.001$ \\
\hline Glucose insulin ratio & $19.5072 \pm 15.29546$ & $57.9260 \pm 20.93578$ & $<0.001$ \\
\hline PAI1 $(\mathrm{pg} / \mathrm{mL})$ & $893.36 \pm 234.97$ & $259.68 \pm 97.75$ & \\
\hline
\end{tabular}

Table 2: Correlation PAI-1 versus all variables in cases.

\begin{tabular}{|lll|}
\hline $\begin{array}{l}\text { Parameters in } \\
\text { cases }\end{array}$ & $\begin{array}{l}\text { r (correlation } \\
\text { coefficient) }\end{array}$ & $\begin{array}{l}\text { P (predictive) } \\
\text { value } \\
\text { BMI }\end{array}$ \\
\hline Waist: hip ratio & $0.557^{* * *}$ & $<0.001$ \\
\hline LH & -0.156 & $<0.001$ \\
\hline FSH & -0.098 & 0.280 \\
\hline LH: FSH ratio & -0.211 & 0.497 \\
\hline PRL & 0.032 & 0.141 \\
\hline TSH & -0.012 & 0.824 \\
\hline Testosterone & -0.010 & 0.931 \\
\hline FBS & $0.429^{* *}$ & 0.947 \\
\hline Fasting insulin & $0.357^{*}$ & 0.002 \\
\hline $\begin{array}{l}\text { Glucose: insulin } \\
\text { ratio }\end{array}$ & $-0.407^{* *}$ & 0.003 \\
\hline Cholesterol & $0.309^{*}$ & 0.029 \\
\hline TRG & $0.492^{* *}$ & 0.000 \\
\hline HDL & $-0.392^{* *}$ & 0.005 \\
\hline LDL & $0.604^{* *}$ & $<0.001$ \\
\hline HOMA-IR & $0.467^{* *}$ & 0.001 \\
\hline
\end{tabular}

Among these we found that LDL alone explained $36.5 \%$ of total variability of PAI-1.

When LDL combined with HOMA-IR: $43.5 \%$ and when fasting insulin also included: $54.9 \%$ of total variability of PAI-1 explained. If we take negative predictive parameters (HDL and glucose: insulin ratio) also then $60.5 \%$ of total variability of PAI-1 is explained.
Table 3: Regression analysis.

\begin{tabular}{|lll|}
\hline $\begin{array}{l}\text { Independent } \\
\text { variables in } \\
\text { PCOS }\end{array}$ & $\begin{array}{l}\text { Percent variation } \\
\text { explained } \\
\left(r^{2} \times 100\right)\end{array}$ & $\begin{array}{l}\text { Regression } \\
\text { coefficient } \\
(r)\end{array}$ \\
\hline LDL (mg/dL) & $36.5 \%$ & 0.604 \\
\hline HOMA-IR & $7 \%$ & 0.650 \\
\hline $\begin{array}{l}\text { Fasting insulin } \\
\text { (Iu/mL) }\end{array}$ & $11.4 \%$ & 0.741 \\
\hline LDL+HOMA-IR & $43.5 \%$ & 0.659 \\
\hline $\begin{array}{l}\text { LDL+HOMA-IR } \\
+ \text { Fasting insulin }\end{array}$ & $54.9 \%$ & 0.741 \\
\hline $\begin{array}{l}\text { HDL + Glucose/ } \\
\text { insulin ratio } \\
\text { (negative } \\
\text { predictive value) }\end{array}$ & $60 \%$ & 0.777 \\
\hline
\end{tabular}

\section{DISCUSSION}

In present study, we found that patients with PCOS had raised plasma PAI-1 levels as compared to controls. The mean level of PAI-1 in PCOS was $(893.36 \pm 234.97$ $\mathrm{pg} / \mathrm{mL})$ and in control $(259.68 \pm 97.75 \mathrm{pg} / \mathrm{mL})$. The sensitivity and specificity of PAI-1 was calculated and it was found that the PAI-1 value at $370.1 \mathrm{pg} / \mathrm{mL}$ is having $100 \%$ sensitivity and $92 \%$ specificity.

Atiomo WU, and Bates SA et al found that PAI-1 levels were significantly higher in PCOS groups than control: a higher PAI-1 activity (mean+SD, 19.7+2.12 arbitrary units (AU) per $\mathrm{mL}$ vs. $10.9+7.9$ AU/mL). ${ }^{1}$ Similarly Francesco, Stefano, Teresa et al found PAI-1 activity increased in PCOS than control having normal BMI 
$(\mathrm{p}<0.05)$; Tarkun, Canturk et al found raised PAI-1 activity in PCOS $(12.8+3.12) \mathrm{U} / \mathrm{mL}$ and control (5.6+2.09) U/mL. ${ }^{2,3}$

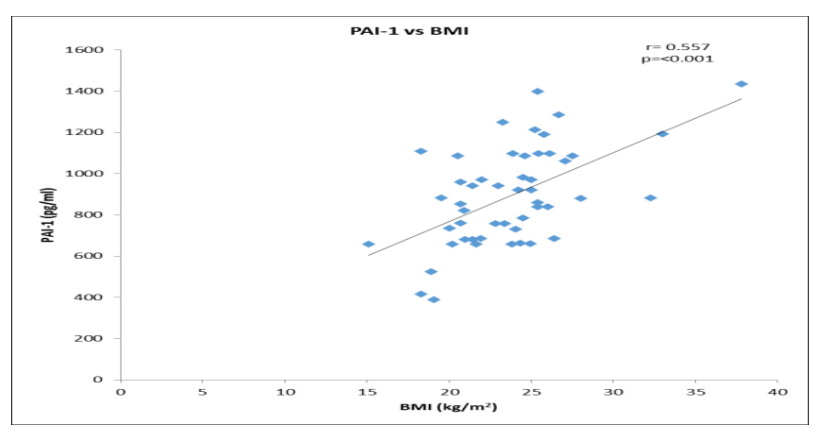

Figure 1: PAI-1 versus BMI.

The difference of PAI-1 level in our study from other is may be due to difference in dilution of sample during assay and the time of collection as PAI-1 level has circadian rhythm and its maximum activity is between 8:00 am to 10 a.m.

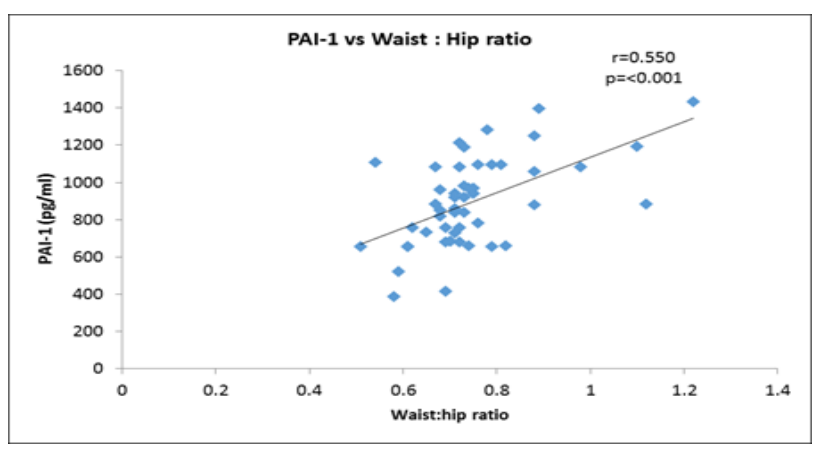

Figure 2: PAI-1 versus Waist: Hip ratio.

Plasminogen activator inhibitor 1 (PAI-1) is a member of the serine protease inhibitor (SERPIN) family, which act as a major regulator of the fibrinolytic system. It inhibits fibrinolytic activity of the tissue-type plasminogen activator (tPA), which generates active plasmin from plasminogen, that then eliminates the fibrin. ${ }^{4}$

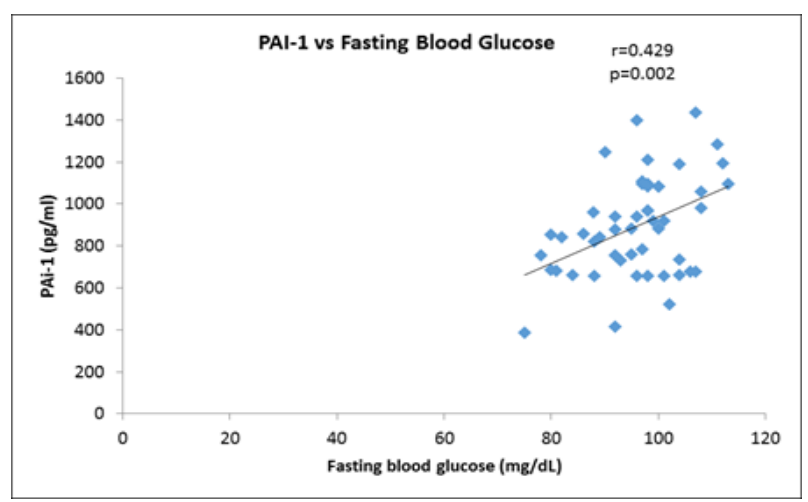

Figure 3: PAI-1 versus fasting blood glucose.

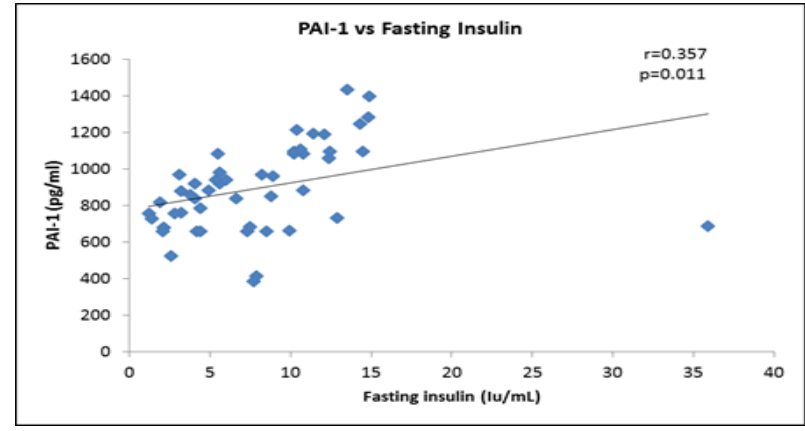

Figure 4: PAI-1 versus fasting insulin.

The PAI-1 plays an important role in development of PCOS. A complex dynamic interrelationship exists between factors such as insulin resistance, obesity, gonadotrophins, insulin like growth factors, the renin angiotensin system and the interleukins and PAI-1.5

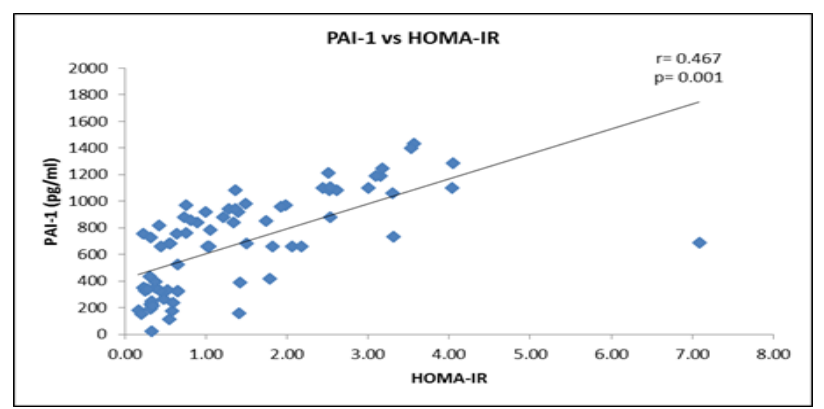

Figure 5: PAI-1 versus HOMA-IR.

The raised level of PAI-1 explains the cause of ovarian dysfunction, ultimately leading to disturbed and endothelial, metabolic, and reproductive dysfunction. ${ }^{5}$ It causes disordered folliculogenesis in PCOS as there is insulin-driven overproduction of PAI-1 with reduction in the amount of plasmin available for extracellular proteolysis..$^{1,6}$

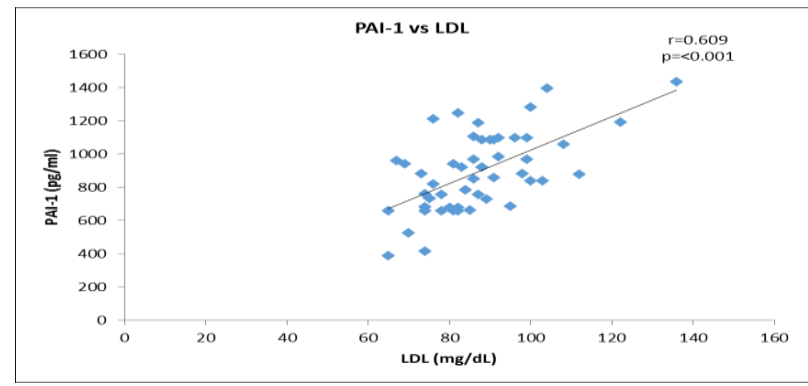

Figure 6: PAI-1 versus LDL.

The majority of PAI-1 is produced within theca (interstitium), whereas expression of plasminogen activators is specific to the granulosa cells. ${ }^{7}$

PAI-1 activity, may also play a key role in fibrinolytic activity in the early stages of placentation. ${ }^{8}$ Antiphospholipid antibodies, known to be associated with 
recurrent pregnancy loss, may exert some of their effect through increasing PAI-1. ${ }^{9}$

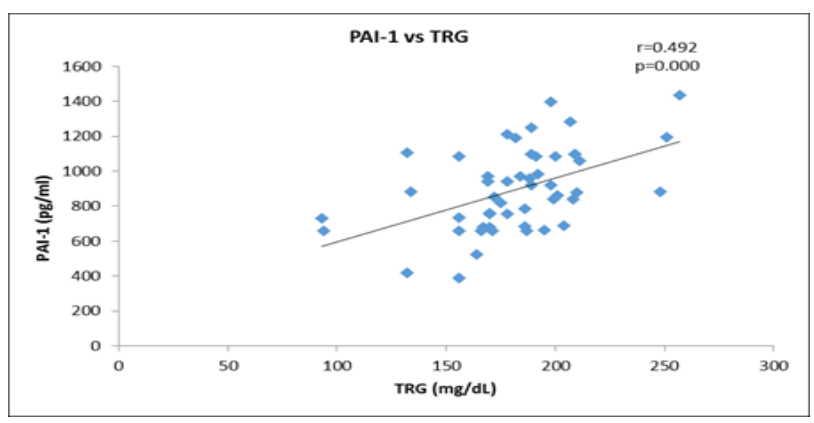

Figure 7: PAI-1 versus TRG.

High-PAI-1 levels are one mechanism that explain link between the finding of polycystic ovaries and recurrent miscarriage. The finding of high PAI- levels in many women with recurrent. ${ }^{10}$ Hyperandrogenism is characteristic of PCOS which impairs follicular development and inhibits ovulation. This occurs due to imbalance in plasminogen. ${ }^{11}$ This resulting in hypertrophied theca (interstitium) prompts a deleterious feedback loop, which then perpetuates testosterone production.

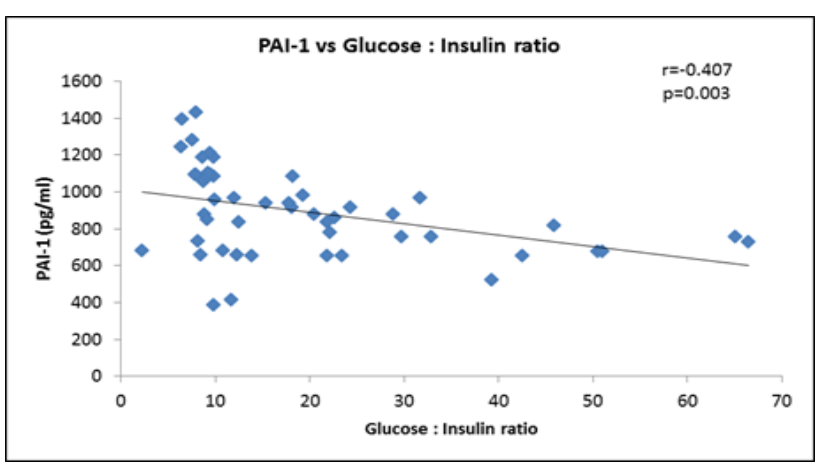

Figure 8: PAI-1 versus glucose: insulin ratio.

There is strong positive correlation between PAI-1 and insulin resistance in normal PCOS, obese PCOS and type 2 DM. This relation is independent of body mass and probably reflect insulin stimulated hepatic PAI-1 production. $^{12}$

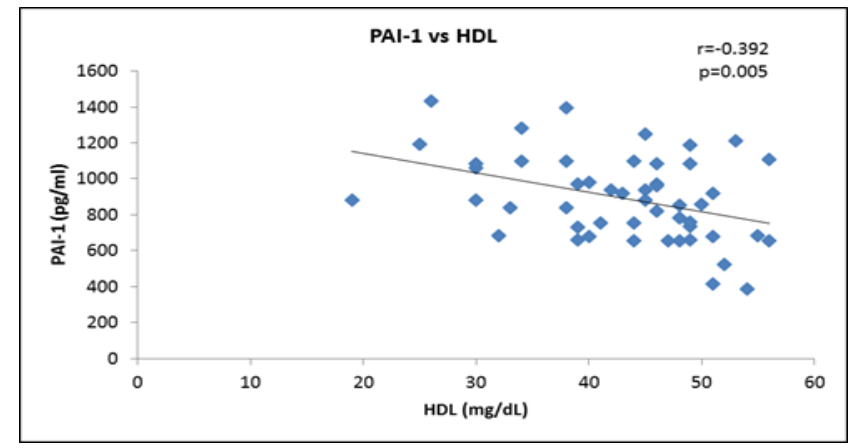

Figure 9: PAI-1 versus HDL.
It has been previously determined that major factor influencing PAI-1 concentration in women was insulin resistance..$^{5,6}$

The mean BMI in present cases was $(23.74 \pm 3.91)$ and in control was $(20.01 \pm 2.32) \mathrm{kg} / \mathrm{m}^{2}$. BMI in cases was significantly increased $(\mathrm{p}<0.001)$. BMI significantly correlated with PAI-1 ( $\mathrm{r}=0.557 ; \mathrm{p}=0.001)$. The mean waist: hip ratio in cases was $(0.74 \pm 0.13)$ and in control was $(0.50 \pm 0.06)$. $\mathrm{W}: \mathrm{H}$ ratio was significantly increased in cases $(r=0.550 ; p<0.001)$. In cases 7 were having $\mathrm{W}: \mathrm{H}$ ratio $>0.85(14 \%)$. In our study group, $26 \%$ of PCOS patients were overweight (BMI $25-29 \mathrm{~kg} / \mathrm{m}^{2}$ ) while $6 \%$ were obese $\left(\right.$ BMI $\left.>30 \mathrm{~kg} / \mathrm{m}^{2}\right)$.

When PCOS patient was compared with control of same BMI group (BMI between 20 to 25), it was found that for same BMI, PAI-1 was however relatively higher in PCOS patient $(840.11 \pm 166.87)$ than control $(262.37 \pm 99.80)(\mathrm{p}=0.001)$.

This finding is relatively consistent with the study of Tarkun I et al where cases $(23.46+2.06)$ and control $(22.9+2.7)$ have almost similar BMI but PAI-1 activity was found more in PCOS patient $(\mathrm{p}=0.05){ }^{3}$

Similarly, in study of Francesco, Stefano, Palomba et al, normal weight $\mathrm{PCOS}(\mathrm{BMI}=23.0+0.3)$ compared with normal weight control $(22.6+0.5)$ it was found that PAI-1 activity was elevated in PCOS even after adjustment of BMI $(\mathrm{p}<0.005){ }^{2}$

In present study, insulin resistance was assessed by fasting glucose; fasting insulin; glucose insulin ratio and HOMA IR (homeostasis model assessment for insulin resistance); lipid profile (LDL, HDL, cholesterol, triglyceride).

In current study, PAI-1 positively correlated with fasting glucose $(r=0.429 \mathrm{p}=0.002) .32 \%$ PCOS patients in our study had raised fasting insulin levels (i.e. more than 9 $\mathrm{IU} / \mathrm{mL})$. When mean level of glucose: insulin ratio of cases (19.5072 \pm 15.29546$)$ was compared with controls $(57.926 \pm 20.935)$ a significant difference was found $(p<0.001)$. Glucose: insulin ratio inversely correlated with PAI-1 $(\mathrm{r}=-0.407, \mathrm{p}=0.003)$. In present study, fasting insulin positively correlated with PAI-1 ( $\mathrm{r}=0.357$; $\mathrm{p}=0.011)$.

The fasting insulin in present cases was $(7.9422 \pm 5.72596) \mathrm{IU} / \mathrm{mL}$ and in control $(1.7880 \pm 0.65149) \quad \mathrm{IU} / \mathrm{mL}$ and significantly correlated with PAI-1 ( $\mathrm{r}=0.357 ; \mathrm{p}=0.011)$. Thus, fasting insulin was raised in cases than in control $(\mathrm{p}<0.001)$. It was raised among those cases whose BMI was $>25 \mathrm{~kg} / \mathrm{m}^{2}(\mathrm{p}=0.002)$, this finding is again consistent with the study of Ilhan Tarkun et al, the fasting insulin in cases $(9.3+3.4)$ was raised in comparison to control $(6.08+2.09)(\mathrm{p}<0.05)$ and moderately correlated with PAI-1 ( $\mathrm{r}=0.315 ; \mathrm{p}=0.021){ }^{3}$ Similarly, we in this study found that serum triglyceride 
(cases: 181.48 $\pm 31.701 \mathrm{mg} / \mathrm{dL}$ control: $152.96 \pm 18.288$ $\mathrm{mg} / \mathrm{dL}$ ) and LDL (cases: $87.06 \pm 14.182 \mathrm{mg} / \mathrm{dL}$ control: $60.96 \pm 14.117 \mathrm{mg} / \mathrm{dL}$ ) levels were increased and HDL was decreased (cases: $42.92 \pm 8.538 \mathrm{mg} / \mathrm{dL}$ control: $52.60 \pm 5.074 \mathrm{mg} / \mathrm{dL})$ in PCOS group as compared to controls ( $\mathrm{p}$ value $<0.001$ ). There was no significant change in serum cholesterol.

PAI-1 significantly correlated with triglyceride $(\mathrm{r}=0.492$ $\mathrm{p}=0.000)$; LDL $(\mathrm{r}=0.604, \mathrm{p}<0.001$; inversely correlated with HDL $(r=-0.392, p=0.005)$.

Based on measurements of fasting glucose and insulin levels, is the homeostatic model assessment (HOMA-IR). Resistance to insulin is diagnosed at HOMA-IR levels $\geq 3$. In our study $22 \%$ of cases had HOMA IR value $>3.0 .{ }^{13}$ In this study, they have taken HOMA - IR cut off value 3.8 and $26 \%$ of cases had value more than 3.8 .

In our study PAI-1 significantly correlated with HOMAIR $(r=0.467 ; p=0.001)$.

A regression analysis was applied keeping PAI-1 as dependent variable and all those positive predictive parameters (BMI; Waist: hip ratio; fasting glucose; fasting insulin; HOMA IR; triglyceride; LDL) as independent variables and we found that LDL alone explained $36.5 \%$ of total variability of PAI-1. When LDL combined with HOMA IR: $43.5 \%$ of PAI-1 variability explained, and when fasting insulin also included: $54.9 \%$ of variability explained.

When negative predictive parameters also taken along with positive (glucose: insulin ratio and HDL) then $60.5 \%$ variability of raised PAI-1 level can be explained.

Whereas in study of Glueck, Sieve, Zhu et al, found following BMI $-10.6 \%, \quad(p<0.001)$; Insulin $13.4 \%$ $(\mathrm{p}<0.001)$; TRG $15.5 \% \quad(\mathrm{p}=0.0009)$ as independent variable affecting PAI-1. ${ }^{14-18}$

Hence raised PAI-1 in PCOS is affected by various parameters: obesity, insulin resistance, dyslipidemia contributes in raised level of PAI-1 in PCOS.

PAI-1 were more likely to have incident diabetes five years later and that PAI-1 may be considered as a predictive factor for the development of type 2 diabetes, independently of insulin resistance and other known risk factors for diabetes. ${ }^{17}$ Previous studies showed that insulin increases PAI-1 synthesis and metformin inhibits insulin-mediated PAI-1 synthesis in vitro. ${ }^{18,19}$ Recently, $\mathrm{Ma}$ et al noted prevention of obesity and insulin resistance in mice lacking PAI- $1 .^{20}$

Limitations of study: Sample size was small ( $\mathrm{n}=75,50$ PCOS patients and 25 controls) and less variation in parameters. We did not include other components of fibrinolytic activities that is plasminogen activators: tPA (tissue type plasminogen activator) and uPA (urokinase type plasminogen activator). We did not observe intra ovarian activity of PAI-1. We did not perform genetic analysis of PAI-1 synthesis.

\section{CONCLUSION}

The elevation of PAI-1 were directly correlated with insulin resistance in PCOS patient; so clinical strategies aimed at reducing insulin resistance may prevent development of atherosclerosis leading to various cardiovascular disease and several menstrual disturbances and infertility in PCOS.

It is required to develop new pharmacological agents that will antagonize PAI-1 and these agents will have the potential to restore proteolytic balance in tissues such as the ovary in order to correct ovulation, treatment for the prevention of PCOS to improve the fertility of patient and to prevent its complications leading to cardiovascular diseases like hypertension, myocardial infarction, type 2 diabetes mellitus etc.

\section{Funding: No funding sources}

Conflict of interest: None declared

Ethical approval: The study was approved by the Institutional Ethics Committee

\section{REFERENCES}

1. Atiomo WU, Bates SA, Condon JE, Shaw S, West $\mathrm{JH}$, Prentice AG. The plasminogen activator system in women with polycystic ovary syndrome. Fertil Steril. 1998;69(2):236-41.

2. Orio F, Palomba S, Cascella T, Tauchmanová L, Nardo LG, Di Biase S, Labella D, Russo T, Tolino A, Zullo F, Colao A. Is plasminogen activator inhibitor-1 a cardiovascular risk factor in young women with polycystic ovary syndrome?. Reprod Biomed Online. 2004;9(5):505-10.

3. Tarkun I, Canturk Z, Turemen E, Tarkun P. 'The Plasminogen Activator System in Young and Lean women with PCOS. Endocrine J. 2004;51(5):467-72.

4. Diamanti-Kandarakis E, Palioniko G, Alexandraki K, Bergiele A, Koutsouba T, Bartzis M. The prevalence of $4 \mathrm{G} 5 \mathrm{G}$ polymorphism of plasminogen activator inhibitor-1 (PAI-1) gene in polycystic ovarian syndrome and its association with plasma PAI-1 levels. Eur J Endocrinol. 2004;150(6):793-8.

5. Atiomo WU, Hilton D, Fox R, Lee D, Shaw S, Friend J, et al. Prentice AG. Immunohistochemical detection of plasminogen activator inhibitor-1 in polycystic ovaries. Gynecol Endocrinol. 2000;14(3):162-8.

6. Sampson M, Kong C, Patel A, Unwin R, Jacobs HS. Ambulatory blood pressure profiles and plasminogen activator inhibitor (PAI-1) activity in lean women with and without the polycystic ovary syndrome. Clin Endocrinol. 1996;45(5):623-9.

7. Peng XR, Hsueh AJ, Ny T. Transient and cellspecific expression of tissue-type plasminogen 
activator and plasminogen-activator-inhibitor type 1 results in controlled and directed proteolysis during gonadotropin-induced ovulation. The FEBS J. 1993;214(1):147-56.

8. Liu K, Liu YX, Hu ZY, Zou RY, Chen YJ, Mu XM, et al. Temporal expression of urokinase type plasminogen activator, tissue type plasminogen activator, plasminogen activator inhibitor type 1 in rhesus monkey corpus luteum during the luteal maintenance and regression. Molecular Cellular Endocrinol. 1997;133(2):109-16.

9. Ieko M. Antiphospholipid antibodies and thrombosis: the putativemechanisms of hypercoagulable state in patients with anticardio lipinantibody. Rinsho Byori. 2000;48:293- 300

10. Gris JC, Schved JF, Aguilar-Martinez P, Arnaud A, Sanchez N. Impact of physical training on plasminogen activator inhibitor activity in sedentary men. Fibrinolysis. 1990;4:97-98.

11. Dunaif A, Wu X, Lee A, Diamanti-Kandarakis E. Defects in insulin receptor signaling in vivo in the polycystic ovary syndrome (PCOS). Am J Physiol Endocrinol Metab. 2001;281:E392-E399.

12. Juhan-Vague I, Roul C, Alessi MC, Ardissone JP, Heim M, Vague P. Increased plasminogen activator inhibitor activity in non insulin dependent diabetic patients. Relationship with plasma insulin. Thromb Haemost. 1989;61:370-3.

13. Nawrocka-Rutkowska J, Ciećwież S, Marciniak A, Brodowska A, Wiśniewska B, Kotlęga D, et al. Insulin resistance assessment in patients with polycystic ovary syndrome using different diagnostic criteria Impact of metformin treatment. Ann Agric Environ Med. 2013;20(3):528-32.

14. Glueck CJ, Papanna R, Wang P, Goldenberg N, Sieve-Smith L. Incidence and treatment of metabolic syndrome in newly referred women with confirmed polycystic ovarian syndrome. Metabolism. 2003;52(7):908-15.

15. Glueck CJ, Papanna R, Wang P, Goldenberg N, Sieve-Smith L. Incidence and treatment of metabolic syndrome in newly referred women with confirmed polycystic ovarian syndrome. Metabolism. 2003;52(7):908-15.

16. Glueck CJ, Phillips H, Cameron D, Sieve-Smith L, Wang P. Continuing metformin throughout pregnancy in women with polycystic ovary syndrome appears to safely reduce first-trimester spontaneous abortion: a pilot study. Fertil Steril. 2001;75:46-52.

17. Glueck CJ, Rorick MH, Schmerler M. Hypofibrinolytic andatherogenic risk factors for stroke. J Lab Clin Med. 1995;125:319-25.

18. Glueck CJ, Wang P, Goldenberg N, Sieve L. Pregnancy loss, polycystic ovary syndrome, thrombophilia, hypofibrinolysis, enoxaparin, metformin. Clin Appl Thromb Hemost 2004;10:32334.

19. Festa A, D’Agostino Jr R, Tracy RP, Haffner SM. Elevatedlevels of acute-phase proteins and plasminogen activator inhibitor-1 predict the development of type 2 diabetes: the Insulin Resistance Atherosclerosis Study. Diabetes. 2002;51:1131-7.

20. Ma LJ, Mao SL, Taylor KL. Prevention of obesity andinsulin resistance in mice lacking plasminogen activator inhibitor1. Diabetes. 2004;53:336-46.

Cite this article as: Sahay S, Jain M, Dash D,

Choubey L, Jain S, Singh TB. Role of plasminogen activator inhibitor type 1 (PAI-1) in PCOS patient. Int J Reprod Contracept Obstet Gynecol 2017;6:4052-8. 